\title{
Treatment of Active Idiopathic Inflammatory Myopathies by Low-Dose Interleukin-2: A Prospective Cohort Pilot Study
}

\author{
Miao Miao · Yuhui Li · Bo Huang · Jiali Chen · Yuebo Jin • \\ Miao Shao $\cdot$ Xia Zhang $\cdot$ Xiaolin Sun (D) J Jing He (D) \\ Zhanguo Li (D)
}

Received: February 14, 2021 / Accepted: March 17, 2021 / Published online: April 14, 2021

(c) The Author(s) 2021

\section{ABSTRACT}

Introduction: Treatment of idiopathic inflammatory myopathies (IIMs) is challenging due to a lack of safe and efficacious medication. Lowdose interleukin-2 (IL-2) treatment emerges as a new option in active IIMs. This study aims to

Miao Miao and Yuhui Li contributed equally to this work.

Supplementary Information The online version contains supplementary material available at https:// doi.org/10.1007/s40744-021-00301-3.

M. Miao · Y. Li · B. Huang · J. Chen · Y. Jin .

M. Shao $\cdot$ X. Zhang $\cdot$ X. Sun $(\varangle) \cdot J$. He $(\varangle)$.

Z. Li $(\bowtie)$

Department of Rheumatology and Immunology, Peking University People's Hospital, Beijing 100044, China

e-mail: sunxiaolin_sxl@126.com

J. He

e-mail: hejing1105@126.com

Z. $\mathrm{Li}$

e-mail: li99@bjmu.edu.cn

M. Miao · Y. Li · B. Huang · J. Chen · Y. Jin

M. Shao - X. Zhang - X. Sun · J. He . Z. Li

Beijing Key Laboratory for Rheumatism Mechanism and Immune Diagnosis (BZ0135), Beijing, China

Z. Li

Peking-Tsinghua Center for Life Sciences, Beijing, China explore the clinical and immunological effects of low-dose IL-2 in patients with active IIMs.

Methods: Eighteen patients with active IIMs were enrolled and received $1 \times 10^{6}$ IU of IL-2 subcutaneously every other day for 12 weeks on top of standard care. The primary endpoint for the trial was change in percentage of regulatory $\mathrm{T}$ (Treg) cells in total $\mathrm{CD}^{+} \mathrm{T}$ cells at week 12 . The secondary endpoints included the International Myositis Assessment and Clinical Studies (IMACS) definition of improvement (DOI), the 2016 American College of Rheumatology (ACR)/European League Against Rheumatism (EULAR) myositis response criteria, safety, and steroid-sparing effect at weeks 12 and 24 .

Results: With low-dose IL-2 treatment, $77.78 \%$ $(14 / 18)$ patients achieved IMACS DOI and $83.33 \%(15 / 18)$ patients met the 2016 ACR/ EULAR myositis response criteria at week 12 . All individual core set measures (CSMs) including PhGA, PGA and HAQ-DI, muscle enzymes, MMT-8 and extramuscular activity were improved at week 12 . The cutaneous dermatomyositis disease area and severity index activity score (CDASI-a) decreased significantly from 7 $(4.5,13)$ to $2(0,7)$ after IL-2 administration $(P<0.001)$. Proportion of Treg cells significantly increased with low-dose IL-2 treatment at week $12(8.97 \%$ [5.77, 9.89\%] vs. $15.2 \%$ [10.4, $17.3 \%], \quad P=0.009)$. There were no serious adverse events.

Conclusions: Low-dose IL-2 was effective in active IIMs and well tolerated. The amelioration 
of disease activity may associate with promotion of Tregs.

Trial Registration: ClinicalTrials.gov identifier, NCT04062019.

Keywords: Low-dose interleukin-2; Idiopathic inflammatory myopathies; Regulatory $\mathrm{T}$ cell

\section{Key Summary Points}

Why carry out this study?

Treg deficiency plays a crucial role in the pathogenesis of idiopathic inflammatory myopathies (IIMs).

Low-dose IL-2 is known to promote expansion of Treg cells and might be potentially therapeutic for patients with IIMs.

\section{What was learned from the study?}

Low-dose IL-2 was effective in treatment of active IIMs and well tolerated.

Low-dose IL-2 promoted the expansion of functional Treg cells in patients with active IIMs.
(ASS) [1]. The standard treatment of IIMs includes glucocorticoids and immunosuppressive agents, which are associated with severe side effects. A proportion of patients are refractory to these treatments, leading to flares and organ damage $[2,3]$.

The pathogenesis of IIMs is not well understood at present, and immunological imbalance is considered to be a key promoter to the disease progress [2]. Regulatory $\mathrm{T}$ (Treg) cells are essential to the maintenance of peripheral tolerance by suppressing the activation and expansion of auto-reactive $\mathrm{T}$ cells and other pathogenic immune cells. It was indicated that Treg cells were impaired in both number and function in multiple autoimmune diseases including IIMs $[4,5]$.

Multiple studies have demonstrated effectiveness of low-dose IL-2 in autoimmune diseases, especially systemic lupus erythematosus [6-9]. However, the effect of IL-2 in IIMs has not been well studied. Immunological and laboratory effects of low-dose IL-2 have been shown in IIMs in previous studies [4] and clinical effects in case report [10]. In this study, we explored clinical and immunological effects, safety and steroid-sparing effect of low-dose IL-2 in patients with active IIMs.

\section{METHODS}

\section{Study Design and Participants}

This was a pilot prospective study in the Department of Rheumatology and Immunology at Peking University People's Hospital (Beijing, China). The study was conducted in accordance with the principles of the Declaration of Helsinki and the International Conference on Harmonisation guidelines on good clinical practice. Peking University People's Hospital Ethics Committee approved the trial. All patients provided written informed consent before enrollment. The trial is registered at https://clinicaltrials.gov (NCT04062019).

Eligible patients were aged $18-70$ years, had a confirmed diagnosis of IIMs according to the 1975 Bohan/Peter criteria [11, 12], or ASS proposed by Solomon et al. [13], IMNM criteria 
proposed by ENMC [14]. All patients had active disease, defined as cutaneous visual analogue scale (VAS) score on Myositis Disease Activity Assessment Tool (MDAAT) $\geq 3 \mathrm{~cm}$ and at least three additional abnormal core set measures (CSMs), or manual muscle test 8 (MMT$8) \leq 125 / 150$ and at least two additional abnormal CSMs [15]. Concomitant use of glucocorticoids and immunosuppressants were permitted before and during the study at stable doses. Glucocorticoid should be $\leq 1 \mathrm{mg} /$ $\mathrm{kg} /$ day prednisone or other hormones with equivalent dose and at a stable dose for at least 4 weeks before enrollment. Immunosuppressant drugs (e.g., cyclosporine or methotrexate) should be stable for at least 12 weeks before enrollment. Detailed information about inclusion and exclusion criteria were provided in online supplementary text.

\section{Procedures}

Low-dose interleukin-2 was injected subcutaneously at a dose of $1 \times 10^{6} \mathrm{IU}$ once every other day for 12 weeks. Patients were then followed up for another 12 weeks. Dose of immunosuppressive drug remained stable throughout the 24-week trial period. Tapering of prednisone was permitted from baseline to week 20 . No changes in dose of prednisone were permitted between weeks 20 and 24 .

Study visits took place on week 0 and every 4 weeks for 24 weeks (Figure S1). Disease activity score included cutaneous dermatomyositis disease area and severity index (CDASI), patient and physician global activity assessment (PGA and PhGA), MMT-8, myositis disease activity assessment tool (MDAAT), extramuscular global and health assessment questionnaire disability index (HAQ-DI). Laboratory parameters including muscle enzymes, erythrocyte sedimentation rate (ESR), C-reactive protein (CRP), complements, and complete blood count were also evaluated at each visit. Safety was assessed at every study visit during the whole study period. Foxp $3^{+}$Treg cells and other immune cells were detected by flow cytometry (Table S1) at each visit. Fasting venous blood in the morning was collected for laboratory examination. High- resolution computed tomography (HRCT) was performed at week 0 and week 24. An overall HRCT score was obtained by quantifying the extent of each abnormality in three lung zones in each lung [16].

In vitro regulatory $\mathrm{T}$ cell suppression assays were performed as described using $\mathrm{CD} 4^{+} \mathrm{CD} 25^{\mathrm{hi}} \mathrm{CD} 127^{\text {lo }}$ Treg cells isolated from peripheral blood of patients before and after IL2 treatment and effector $\mathrm{T}$ cells $\left(\mathrm{CD} 4^{+} \mathrm{CD} 25^{-} \mathrm{T}\right.$ cell) from healthy controls. Peripheral $\mathrm{CD} 4{ }^{+} \mathrm{CD} 25^{\mathrm{hi}} \mathrm{CD} 127^{\mathrm{lo}}$ Treg cells from patients and Teff cells from healthy controls were sorted using Moflo Astrios EQ (Beckman Coulter). In each experiment, Teff cells were stained using Cell Trace CFSE (Thermo Fisher) according to the manufacturer's instructions. Treg and Teff cells were then mixed at the ratio of $1: 1$ per well, then stimulated with anti-CD2/CD3/CD28 beads (Treg Suppression Inspector, Miltenyi Biotec) at a 1:1 Teff + Treg: beads ratio in complete RPMI media for 4 days. In this assay, $\mathrm{T}$ cell proliferation is indicated by dilution of Cell Trace CFSE.

\section{Outcomes}

The primary endpoint for the trial was change in percentage of regulatory $\mathrm{T}$ cells in total $\mathrm{CD} 4^{+} \mathrm{T}$ cells at week 12 . The secondary endpoint for the trial included the International Myositis Assessment and Clinical Studies (IMACS) definition of improvement (DOI), the 2016 American College of Rheumatology (ACR)/European League Against Rheumatism (EULAR) myositis response criteria [16], safety, and steroid-sparing effect. IMACS DOI includes three of any of the six CSMs improved by $\geq 20 \%$, with no more than two CSMs worsening by $\geq 25 \%$ (worsening measure cannot include the MMT-8) [17, 18]. 2016 ACR/EULAR myositis response criteria definite that a total score improvement (a metric derived from the 2016 ACR-EULAR myositis response criteria, which corresponds to the magnitude of improvement) of $\geq 20$ represents minimal improvement, a score of $\geq 40$ represents moderate improvement and a score of $\geq 60$ represents major improvement [19]. 


\section{Statistical Analysis}

Descriptive statistics were evaluated for baseline demographic, clinical and laboratory variables, and frequency of patients meeting DOI. Wilcoxon signed-rank test was used for continuous variable and Chi-squared test for categorical variables within each of the treatment cycles (baseline vs. weeks 4, 8, 12, 24; week 12 vs. week 24). Pearson correlation analysis was performed between total improvement score and change of $\mathrm{T}$ cell subsets or baseline characters. Endpoints were assessed in all patients who completed at least 1 month of treatment. All patients who had ever received at least one dose of IL-2 were included in the safety assessment population. Differences were considered to be significant if $P$ values were less than 0.05 . Statistical analysis for all endpoints was performed using SPSS v.22.0. Figures were prepared using Adobe Illustrator CS6 and GraphPad Prism (version 8).

\section{RESULTS}

\section{Patient Characteristics}

Between September 19, 2019, and April 24, 2020, 18 patients with IIMs fulfilled the eligibility criteria and were enrolled. All of the treated patients completed the 12 -week treatment period and 17 completed the 12-week follow-up period. One withdrew at week 12 due to poor response. Table S2 and S3 summarized the patients' baseline characteristics, demographic data, and details of previous and current treatment. In this study, there were ten patients with DM, six patients with ASS, and two patients with IMNM (Table S2, S3).

Proximal muscle weakness was present in $44.44 \%(8 / 18)$, rash in $83.33 \%(15 / 18)$, arthritis in $22.22 \%(4 / 18)$, and myositis-associated interstitial lung disease (ILD) in 55.56\% (10/18) of all IIMs patients. Mechanic's hands, heliotrope rash, Gottron's sign/papules, V sign, and Shawl sign accounted for 27.78, 55.56, 50, 22.22 , and $5.56 \%$ of all patients, respectively (Table S2, S3).

Antibodies were represented, with $61 \%$ of the cohort possessing at least one myositis- associated autoantibody as determined by Western blot. This included anti-synthetase antibodies $(n=6,33.33 \%)$, anti-melanoma differentiation-associated protein 5 (MDA5) $(n=2$, $11.11 \%)$, anti-Mi- $2 \alpha(n=1,5.56 \%)$, anti-SRP $(n=1,16.67 \%)$, and anti-HMGCR $(1,5.56 \%)$. No patient was positive for anti-PM/Scl 100, anti-NXP2, anti-TIF- $1 \gamma$ or anti-Mi- $2 \beta$ (Table S2, S3).

\section{Efficacy}

After 3 months of treatment with low-dose IL-2, 14 out of $18(77.78 \%)$ patients were responders and reached the IMACS DOI (Fig. 1a, b). The responders included nine DM patients and five ASS patients. Non-responders included two IMNM patients, one DM patient, and one ASS patient. Two of four non-responders at week 12 responded at week $24 ; 15 / 18(83.33 \%)$ met the 2016 ACR/EULAR myositis response criteria. The total improvement score was 23.8 (8.1-37.5) at week 12 and $22.5(2-37.5)$ at week 24 , the end of follow-up, with eight $(44.44 \%)$, six $(33.33 \%)$ and one $(5.56 \%)$ of patients achieving minimal, moderate, and major improvement, respectively (Fig. 1b). MMT-8 was increased from $129(120,141)$ at baseline to $135(126,143)(P=0.017)$ at week 12 and 140 $(128,145)(P=0.043)$ at week 24 . Details of improvements in other CSMs including PhGA, PGA and HAQ-DI, muscle enzymes, and extramuscular activity were summarized in Table 1 and Table S4.

The extramuscular global, primarily driven by skin rash in our study, showed a median of $50 \%$ improvement in all patients. The cutaneous dermatomyositis disease area and severity index activity score (CDASI-a) was decreased significantly from $7(4.5,13)$ to $2(0,7)$ after IL-2 administration $(P<0.001)$. The improvement of skin rash included mechanic's hands (in four of the five patients with this manifestation), heliotrope rash (nine of ten patients), Gottron's sign/papules (six of nine patients), $\mathrm{V}$ sign (all of four patients with this manifestation), Shawl sign (in the one patient with this manifestation), and periungual erythema (four of five patients) (Table 1). 

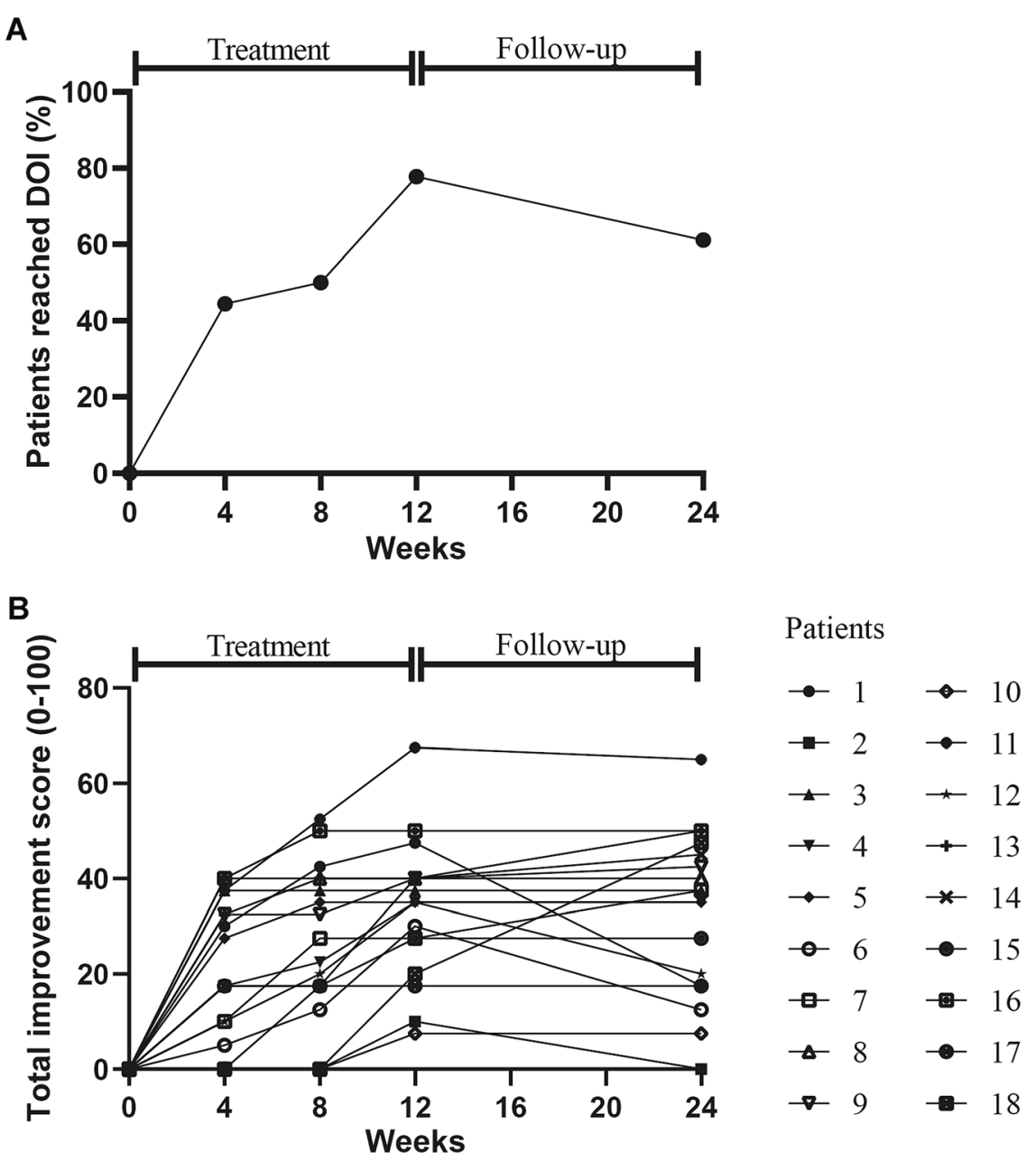

Fig. 1 Clinical response to low-dose IL-2 treatment. International Myositis Assessment and Clinical Studies (IMACS) definition of improvement (DOI) (a) and 2016

Daily dose of prednisone decreased from $12.25(5,15) \mathrm{mg}$ at baseline to $10(4.37,15) \mathrm{mg}$ $(P=0.016)$ at week 12 and $10(2.5,12.5) \mathrm{mg}$ $(P=0.013)$ at week 24 (Table 1$)$. There was a trend that total HRCT score was improved at week 24 (82 [25, 397.5] vs. 53 [10, 360], $P=0.125$ ) (Table 1), although there was no statistic difference. Besides, there was no obvious improvement of lung function (Table S5).

\section{Safety}

Low-dose IL-2 therapy was well tolerated at a daily dose of $1 \times 10^{6} \mathrm{IU}$. Safety data during the treatment period were shown in Table S6. No
American College of Rheumatology-European League Against Rheumatism myositis response criteria (b)

serious adverse events were observed. The most common adverse events were injection-site reactions, manifested as injection-site pain, redness, and swelling, which were observed in five of $18(27.78 \%)$ patients. Transient influenza-like symptoms and transient fever occurred in two (11.11\%) patients. These symptoms were resolved without intervention. There were no significant changes in routine laboratory examinations including white blood cell count, hemoglobin, platelet count, kidney function, or blood glucose over the 24-week trial period. 
Table 1 Response of IIMs patients to low-dose IL-2 treatment $(n=18)$

\begin{tabular}{|c|c|c|c|c|c|}
\hline Characteristics & $\begin{array}{l}\text { Baseline } \\
\text { (week 0) }\end{array}$ & Week 12 & Week 24 & $\begin{array}{l}P \text { value (week } 12 \\
\text { vs. } 0 \text { ) }\end{array}$ & $\begin{array}{l}P \text { value (week } 24 \\
\text { vs. } 0 \text { ) }\end{array}$ \\
\hline \multicolumn{6}{|l|}{ Core set measures } \\
\hline PhGA-VAS, median (range) & $5(4,5.5)$ & $2.5(2,4)$ & $\begin{array}{l}2.25(1.25 \\
3.75)\end{array}$ & $<0.001$ & 0.002 \\
\hline PGA-VAS, median (range) & $5(3.5,7)$ & $3(2,4)$ & $2(1,3.5)$ & $<0.001$ & 0.002 \\
\hline $\begin{array}{l}\text { MMT-8 (0-150), median } \\
\text { (range) }\end{array}$ & $129(120,141)$ & $\begin{array}{c}135(126 \\
143)\end{array}$ & $\begin{array}{l}140(128 \\
145)\end{array}$ & 0.017 & 0.043 \\
\hline $\begin{array}{l}\text { HAQ-DI (1-3), median } \\
\text { (range) }\end{array}$ & $2(0.4,5)$ & $2(0.15,3.15)$ & $2(0.15,3.15)$ & 0.007 & 0.277 \\
\hline $\begin{array}{l}\text { Extramuscular disease, VAS } \\
(0-10)\end{array}$ & $5(4,6)$ & $3(2,4)$ & $2(1,3.5)$ & 0.001 & 0.008 \\
\hline ALT, median (range) & $15(11,23.5)$ & $14(10,18)$ & $\begin{array}{c}13.5(11 \\
22.5)\end{array}$ & 0.209 & 0.609 \\
\hline AST, median (range) & $23(18,31)$ & $18(14,23)$ & $\begin{array}{c}20.5(17 \\
26.5)\end{array}$ & 0.004 & 0.35 \\
\hline LDH, median (range) & $\begin{array}{l}228(162.5 \\
256)\end{array}$ & $\begin{array}{l}188(149 \\
251)\end{array}$ & $\begin{array}{l}205(181 \\
245)\end{array}$ & 0.023 & 0.638 \\
\hline CK, median (range) & $\begin{array}{l}125(51.5 \\
331)\end{array}$ & $\begin{array}{c}67(49.5 \\
208)\end{array}$ & $\begin{array}{l}102(10.1 \\
168)\end{array}$ & 0.005 & 0.875 \\
\hline $\begin{array}{l}\text { CDASI-a }(0-100), \text { median } \\
\text { (range) }\end{array}$ & $7(4.5,13)$ & $2(0,7)$ & $1(0,3)$ & $<0.001$ & 0.006 \\
\hline $\begin{array}{l}\text { CDASI-d (0-32), median } \\
\quad \text { (range) }\end{array}$ & $1(0,8.5)$ & $0(0,8.5)$ & $0(0,8.5)$ & 0.180 & 0.972 \\
\hline $\begin{array}{l}\text { Fatigue-VAS }(0-10), \text { median } \\
\quad \text { (range) }\end{array}$ & $2(1,4.5)$ & $2(0.5,3.5)$ & $1(0.5,2.5)$ & 0.015 & 0.167 \\
\hline Mechanic's hands, $n$ (\%) & $5(27.78)$ & $1(5.56)$ & $2(11.11)$ & 0.125 & 0.206 \\
\hline Heliotrope rash, $n(\%)$ & $10(55.56)$ & $1(5.56)$ & $2(11.11)$ & 0.004 & 0.017 \\
\hline Gottron's sign/papules, $n(\%)$ & $9(50)$ & $3(16.67)$ & $3(16.67)$ & 0.031 & 0.031 \\
\hline $\mathrm{V}$ sign, $n(\%)$ & $4(22.22)$ & $0(0)$ & $1(5.56)$ & 0.125 & 0.148 \\
\hline Shawl sign, $n(\%)$ & $1(5.56)$ & $0(0)$ & $0(0)$ & $>0.99$ & $>0.99$ \\
\hline Periungual erythema, $n(\%)$ & $5(27.78)$ & $1(5.56)$ & $1(5.56)$ & 0.125 & 0.125 \\
\hline Arthritis, $n$ (\%) & $4(22.22)$ & $2(11.11)$ & $4(22.22)$ & 0.500 & $>0.99$ \\
\hline ILD, $n(\%)$ & $10(55.56)$ & $10(55.56)$ & $10(55.56)$ & $>0.99$ & $>0.99$ \\
\hline Malignancy, $n(\%)$ & $0(0)$ & $0(0)$ & $0(0)$ & $>0.99$ & $>0.99$ \\
\hline ESR, median (range) & $\begin{array}{c}14(6.25 \\
22.25)\end{array}$ & $23(7.5,29.5)$ & $\begin{array}{l}13.5(7.25 \\
23)\end{array}$ & 0.398 & 0.9 \\
\hline
\end{tabular}


Table 1 continued

\begin{tabular}{lllllc}
\hline Characteristics & $\begin{array}{l}\text { Baseline } \\
\text { (week 0) }\end{array}$ & Week 12 & Week 24 & $\begin{array}{l}\boldsymbol{P} \text { value (week 12 } \\
\text { vs. 0) }\end{array}$ & $\begin{array}{l}\boldsymbol{P} \text { value (week 24 } \\
\text { vs. 0) }\end{array}$ \\
\hline CRP, median (range) & $0.74(0,2.68)$ & $1.9(0,10.25)$ & $0.5(0,0.95)$ & 0.715 & 0.225 \\
C3, median (range) & $0.89(0,1.05)$ & $1(0,1.05)$ & $0.9(0,1.03)$ & $\mathbf{0 . 0 0 8}$ & 0.507 \\
C4, median (range) & $0.19(0.17$, & $0.21(0.18$, & $0.2(0.17$, & $\mathbf{0 . 0 0 6}$ & 0.576 \\
& $0.23)$ & $0.29)$ & $0.23)$ & & \\
Prednisone, median (range) & $12.25(5,15)$ & $10(4.37,15)$ & $10(2.5,12.5)$ & $\mathbf{0 . 0 1 6}$ & $\mathbf{0 . 0 1 3}$ \\
$\begin{array}{c}\text { Total HRCT score, median } \\
\text { (range) }\end{array}$ & $82(25,397.5)$ & - & $53(10,360)$ & - & 0.125 \\
\hline
\end{tabular}

Data are presented as median (IQR), mean $\pm \mathrm{SD}$ or $n$ (\%)

$I I M s$ idiopathic inflammatory myopathies, $P h G A$ physician's global assessment of disease, $V A S$ visual analog scale, $P G A$ patient's global assessment of disease, MMT-8 Manual Muscle Test-8, HAQ-DI the health assessment questionnaire disability index, $A L T$ alanine transaminase, $A S T$ aspartate transaminase, $L D H$ lactate dehydrogenase, $C K$ creatinine kinase, CDASI-a Cutaneous Dermatomyositis Disease Area and Severity Index Activity Score, CDASI-d Cutaneous Dermatomyositis Disease Area and Severity Index Damage Score. MDAAT myositis disease activity assessment tool. ILD, interstitial lung disease, ESR erythrocyte sedimentation rate, CRP C-reactive protein, $C 3$ complement 3, C4 complement 4, HRCT high-resolution computed tomography

\section{Immunological Analysis}

The proportion of Treg cells in $\mathrm{CD} 4^{+} \mathrm{T}$ cells was increased at week 12 compared with that at baseline $(8.97 \%[5.77,9.89 \%]$ vs. $15.2 \%[10.4$, 17.3\%], $\quad P=0.009)$. Similarly, the absolute number of Treg cells were increased from 49.2 $(39.3,79.14)$ to $57.61(36.68,84.16)$ at week 4 $(P=0.047)$ (Fig. 2a). Elevated number of Treg cells was correlated with increased total improvement score $(r=0.688, \quad P=0.002$, Fig. 3a, b). The proportion and absolute number of Teff cells were significantly decreased by week 12. At the same time, Treg/Teff were also significantly elevated $(0.1[0.06,0.11]$ vs. 0.18 $[0.12,0.21], P=0.046$ ) (Fig. 2b). Neither proportion nor absolute number of Th17 cells significantly changed (Figure S2).

Significant decreases of $\mathrm{CD}^{-} \mathrm{CD} 56^{-} \mathrm{CD} 19^{+} \mathrm{B}$ cells and follicular helper $\mathrm{T}$ (Tfh) cells were noted in both proportion and number at week 4, 8, 12 (Fig. 4a, b). The absolute number and proportion of $\mathrm{CD}^{-} \mathrm{CD} 56^{+} \mathrm{CD} 16^{+} \mathrm{NK}$ cells were obviously increased in IIMs patients at week 4, 8,12 . However, the number of Tfh cells, B cells and NK cells reverted to baseline levels after 24 weeks (Fig. 4c).

We next evaluated the function of Treg cells. There was an increased suppressive function of Treg cell after IL-2 treatment. The relative proportion of proliferation and division index of Teff cells were obviously decreased after IL-2 treatment compared to that at baseline ( $P=0.004$ and $P=0.022$, respectively) (Fig. 5).

In addition, we analyzed three subsets of Treg cells, including active-Treg (aTreg) and resting-Treg (rTreg) and non-functional Treg (non-Treg) cells (Figure S3). There were decrease of aTreg and rTreg cells in IIMs, while an increase of aTreg and an increase of CD25 levels on aTreg were observed after IL-2 therapy $(P=0.028, P=0.028$, respectively, Figure S3, S4).

\section{DISCUSSION}

This was a prospective pilot study to explore the clinical and immunological effects, safety, and tolerability of low-dose IL-2 treatment in patients with active IIMs. After 3 months of treatment, $77.78 \%$ of patients were responders 

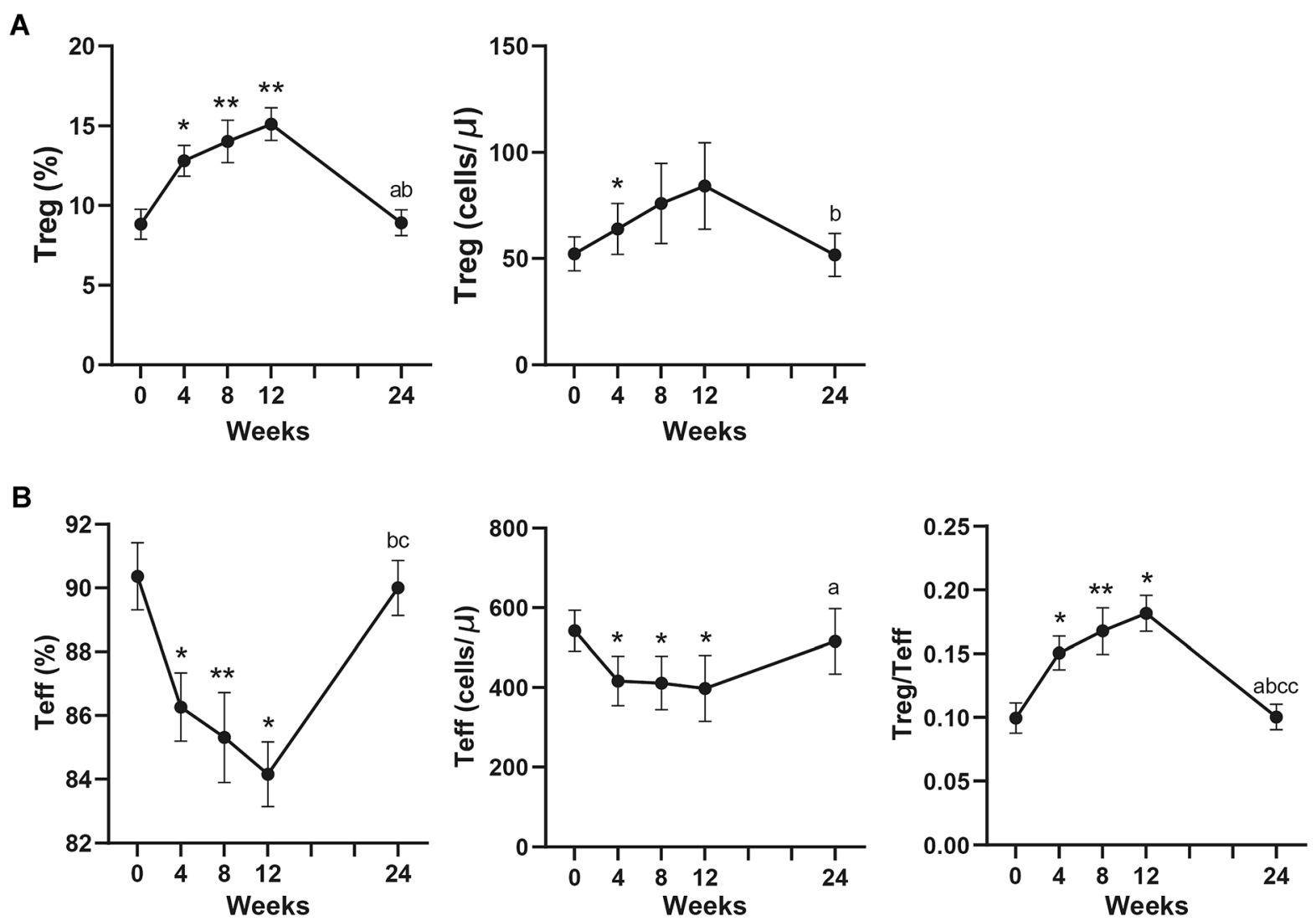

Fig. 2 Changes of percentage and absolute number of Foxp $3^{+}$Treg, Teff and Treg/Teff in peripheral blood of IIMs patients after the treatment of low-dose IL-2. Treg, regulatory $\mathrm{T}$ cells. Teff, effector $\mathrm{T}$ cells. IIMs, idiopathic

inflammatory myopathies. ${ }^{*} P<0.05$; ${ }^{* *} P<0.01$; compared to week 0 . a $P<0.05$ compared to week 4 . b $P<0.05$ compared to week 8 . c $P<0.05$; cc, $P<0.01$ compared to week 12
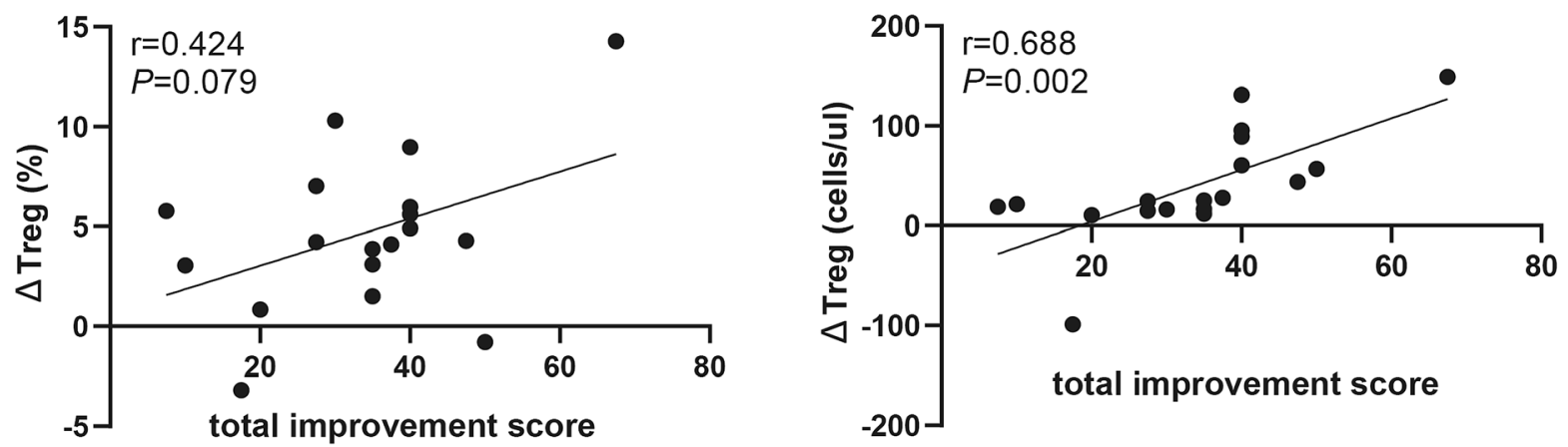

Fig. 3 The correlation between change of Treg cell and total improvement score 
A
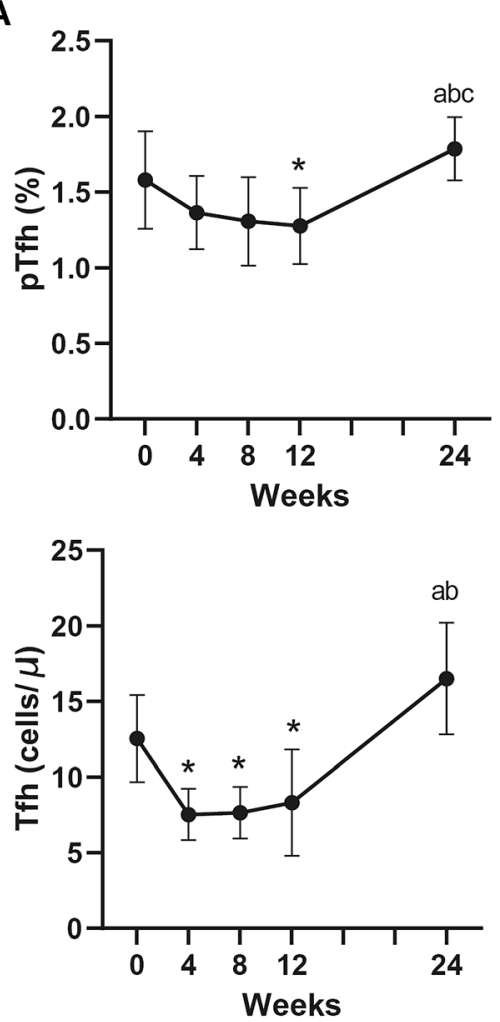

B
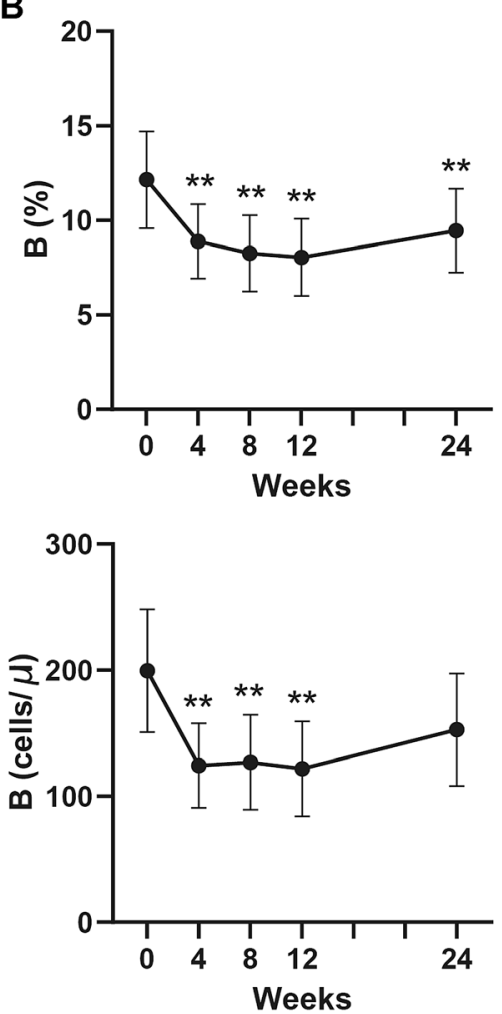

C
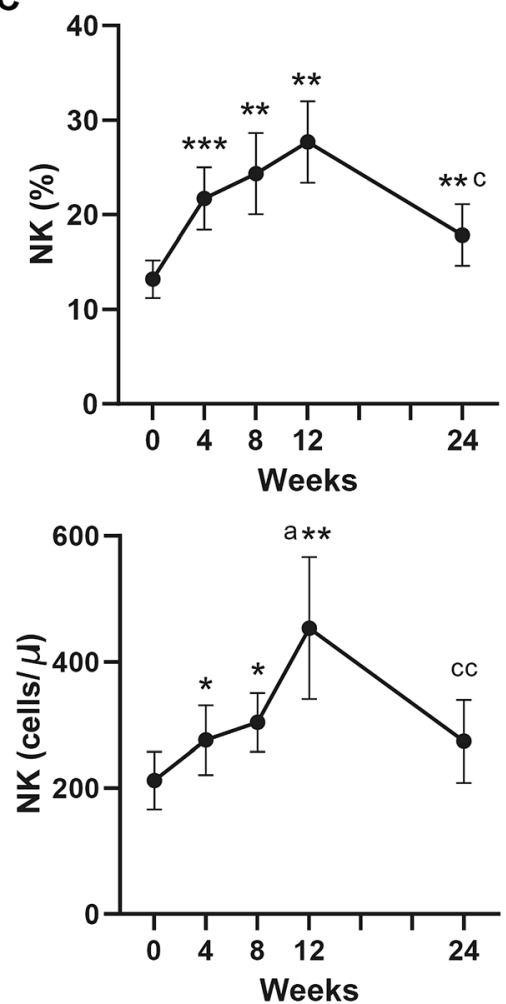

Fig. 4 Changes of percentage and absolute number of Tfh, B, and NK cells in peripheral blood of IIMs patients after the treatment of low-dose IL-2. Tfh, follicular helper $\mathrm{T}$ cells. IIMs, idiopathic inflammatory myopathies.
${ }^{*} P<0.05$; ${ }^{* *} P<0.01$; compared to week 0 . a $P<0.05$ compared to week 4 . b $P<0.05$ compared to week 8 . c $P<0.05$; cc, $P<0.01$ compared to week 12

study, patients received 1 million IU/day of IL-2 from day 1 to day 5 (the induction period), and then every 2 weeks from day 15 to day 180 (the maintenance period). Treg was significantly upregulated on day 8 versus baseline as well as at day 180 versus baseline, indicating that lowdose IL-2 effects on Tregs were maintained over time across diseases [9]. Treg proportion was at a relatively lower level with the dose of 1 million IU every 2 weeks compared to the level in the induction period [9]. We assume that 1 million IU/week is probably the dose to maintain the level of Treg, but further studies are still needed. Although treatment-related increases in Treg cells were transient, total improvement score were maintained in most of patients $(77.78 \%)$ in our study. In addition, we found further increased improvements in some of the patients $(27.78 \%)$ after withdrawal of Low-dose IL-2. It 

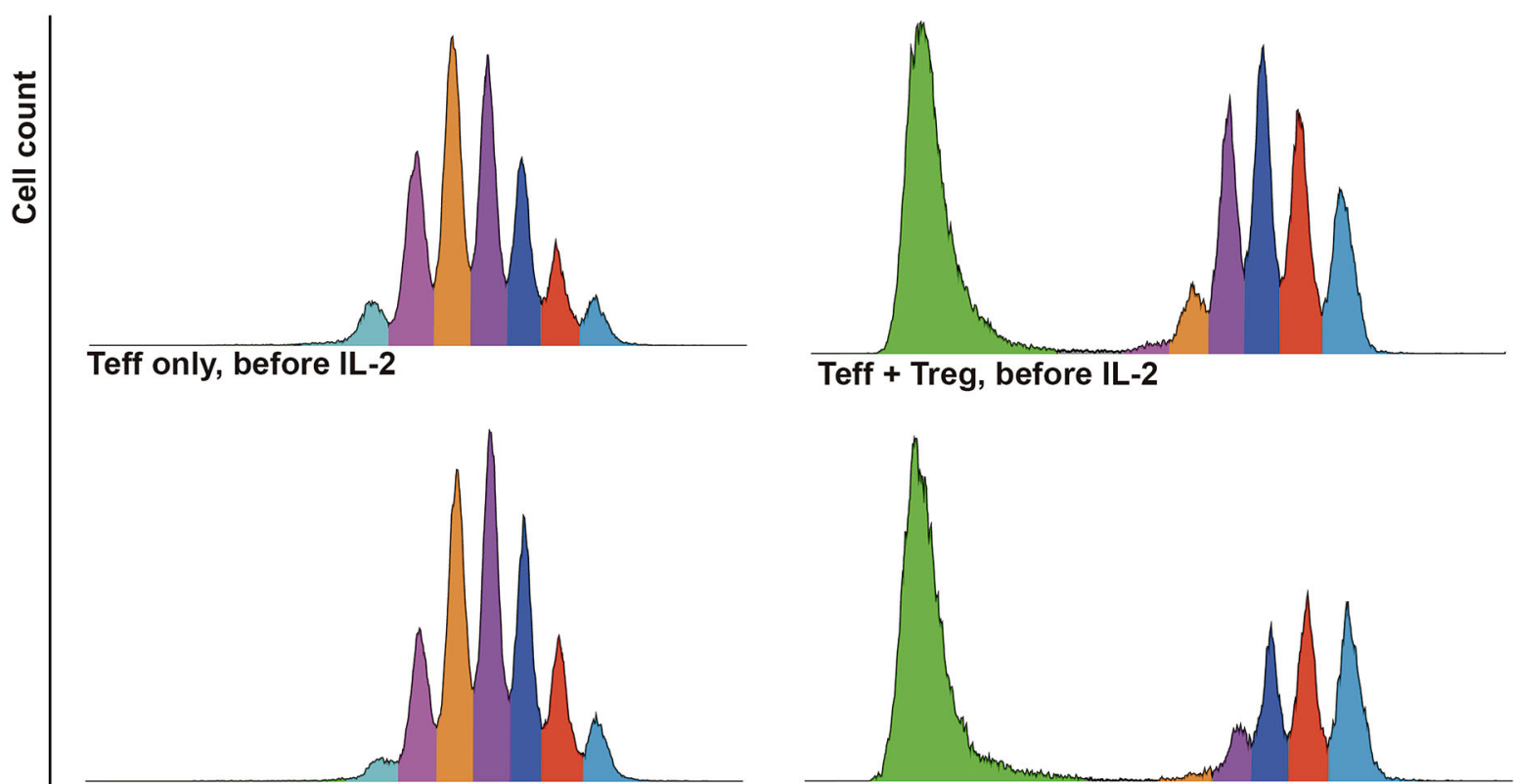

Teff only, after IL-2

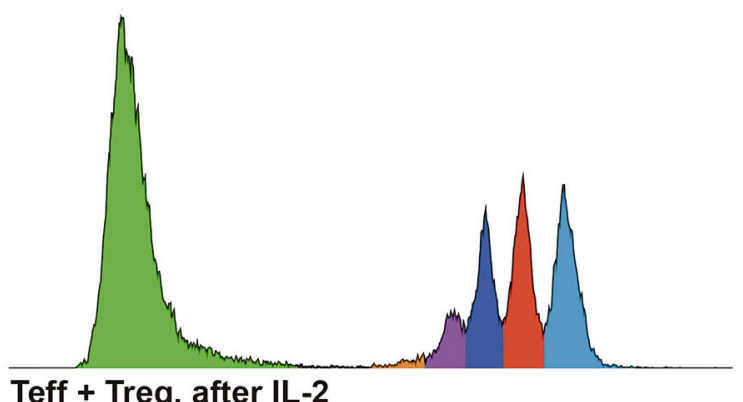

Teff + Treg, after IL-2

CFSE
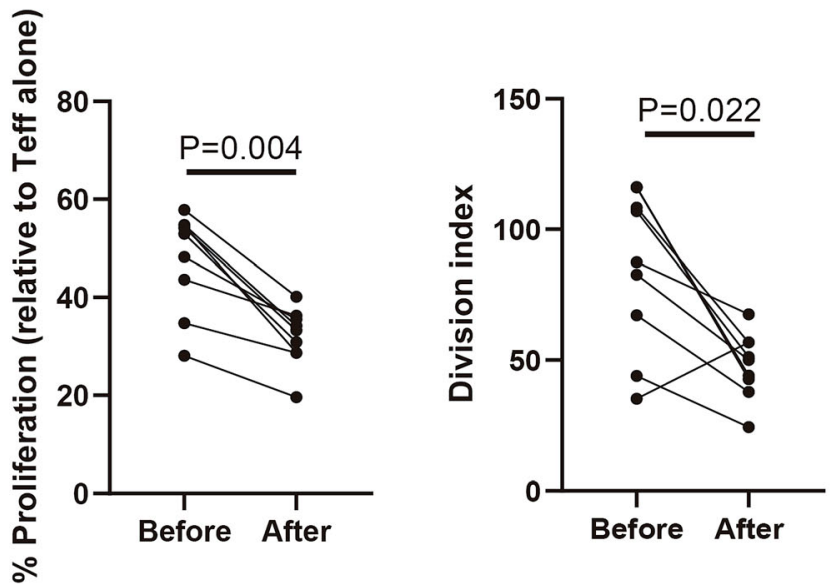

Fig. 5 Change of suppressive function of Treg cells after low-dose IL-2 treatment $(n=8)$. Treg, regulatory T cells. Teff, effector T cells. CFSE, carboxyfluorescein diacetate succinimidyl ester

appears that the effects of low-dose IL-2 lasted in the 3-month follow-up period even though Treg cells decreased during this period.

Clinical response intensity also associated with subtypes of IIMs. Despite limitation of sample size, we found poor response to lowdose IL-2 in IMNM patients and good response in DM (including anti-MDA5-positive dermatomyositis). It seems like that low-dose IL-2 was more efficacious in rash than in muscle. The potential mechanisms remain unclear, which might relate to different characters of different disease subtypes.

Absolute number and proportion of B cells and Tfh cells were decreased, which suggest that low-dose IL-2 therapy suppress immune responses in the germinal centers of lymphatic tissues. Absolute number and proportion of NK cells were increased. The results are in agreement with those of previous studies of low-dose IL-2 in a variety of autoimmune diseases [9,21-25]. 
Limitations of this trial include the small sample size and the lack of control group. Background treatment was not changed except tapering of GCs in this trial, indicating that the outcomes of the patients were contributed mainly by low-dose IL-2. The results are encouraging, but randomized placebo-controlled trials with a larger cohort are needed in future.

\section{CONCLUSIONS}

Low-dose IL-2 treatment was clinically efficacious in patients with active IIMs, with improvement of Treg cell deficiency.

\section{ACKNOWLEDGEMENTS}

We would like to thank all of the patients, study investigators, and staff who were involved with this study

Funding. This work and the journal's Rapid Service Fee were supported by the following funds: the National Natural Science Foundation of China (U1903210, 31870879, 81971520); the Peking-Tsinghua Center for Life Sciences; Peking University People's Hospital Research and Development Foundation (RDX2019-03); Peking University Clinical Scientist Program (BMU2019LCKXJ004) and the Clinical Medicine Plus X-Young scholars Project of Peking University (PKU2020LCXQ018), supported by the Fundamental Research Funds for the Central Universities.

Authorship. All named authors meet the International Committee of Medical Journal Editors (ICMJE) criteria for authorship for this article, take responsibility for the integrity of the work as a whole, and have given their approval for this version to be published.

Authors' Contributions. Zhanguo Li, Jing $\mathrm{He}$, Xiaolin Sun, Yuhui Li and Miao Miao contributed to study conception and design. Yuhui Li, Miao Miao, Bo Huang, Jiali Chen, Yuebo Jin, Miao Shao and Xia Zhang performed data acquisition and analysis. Zhanguo Li, Jing He, Xiaolin Sun, Yuhui Li and Miao Miao were involved in data interpretation. All authors participated in the drafting, critical revision, and approval of the final version of the manuscript.

Prior Presentations. This work won a Celltrion Abstract Award at the Asia-Pacific League of Associations for Rheumatology (APLAR) 2020 Virtual Congress and was virtually presented at the congress on IIM, SSc, SjS 2 Session; October 25,2020 .

Disclosures. All of the authors (Miao Miao, Yuhui Li, Bo Huang, Jiali Chen, Yuebo Jin, Miao Shao, Xia Zhang, Xiaolin Sun, Jing He, Zhanguo Li) have nothing to disclose.

Compliance with Ethics Guidelines. The approval (Reference Number: 2019PHB089) was obtained from the Peking University People's Hospital Ethics Committee prior to initiation of the study. Written informed consent (for participation and publication) was acquired from all patients involved. The study was performed in accordance with the Helsinki Declaration of 1975 and its later amendments.

Data Availability. The datasets generated during and/or analyzed during the current study are available from the corresponding author on reasonable request.

Open Access. This article is licensed under a Creative Commons Attribution-NonCommercial 4.0 International License, which permits any non-commercial use, sharing, adaptation, distribution and reproduction in any medium or format, as long as you give appropriate credit to the original author(s) and the source, provide a link to the Creative Commons licence, and indicate if changes were made. The images or other third party material in this article are included in the article's Creative Commons licence, unless indicated otherwise in a credit line to the material. If material is not included in the article's Creative Commons licence and your intended use is not permitted by statutory regulation or exceeds the permitted use, you 
will need to obtain permission directly from the copyright holder. To view a copy of this licence, visit http://creativecommons.org/licenses/by$\mathrm{nc} / 4.0 /$.

\section{REFERENCES}

1. Mariampillai K, Granger B, Amelin D, Guiguet M, Hachulla E, Maurier F, et al. Development of a new classification system for idiopathic inflammatory myopathies based on clinical manifestations and myositis-specific autoantibodies. JAMA Neurol. 2018;75(12):1528.

2. Dalakas MC. Immunotherapy of myositis: issues, concerns and future prospects. Nat Rev Rheumatol. 2010;6:129-37.

3. Marie I, Mouthon L. Therapy of polymyositis and dermatomyositis. Autoimmun Rev. 2011;11:6-13.

4. Zhang SX, Wang J, Sun HH, Zhang JQ, Liu GY, Luo $\mathrm{J}$, et al. Circulating regulatory $\mathrm{T}$ cells were absolutely decreased in dermatomyositis/polymyositis patients and restored by low-dose IL-2. Ann Rheum Dis. 2019. https://doi.org/10.1136/annrheumdis2019-216246.

5. Feng M, Guo H, Zhang C, Wang Y, Liang Z, Zhao X, et al. Absolute reduction of regulatory $T$ cells and regulatory effect of short-term and low-dose IL-2 in polymyositis or dermatomyositis. Int Immunopharmacol. 2019;77:105912.

6. He J, Zhang R, Shao M, Zhao X, Miao M, Chen J, et al. Efficacy and safety of low-dose IL-2 in the treatment of systemic lupus erythematosus: a randomised, double-blind, placebo-controlled trial. Ann Rheum Dis. 2020;79:141-9.

7. He J, Zhang X, Wei Y, Sun X, Chen Y, Deng J, et al. Low-dose interleukin-2 treatment selectively modulates CD4(+) T cell subsets in patients with systemic lupus erythematosus. Nat Med. 2016;22: 991-3.

8. Humrich JY, Spee-Mayer C, Siegert E, Bertolo M, Rose A, Abdirama D, et al. Low-dose interleukin-2 therapy in refractory systemic lupus erythematosus: an investigator-initiated, single-centre phase 1 and 2a clinical trial. Lancet Rheumatol. 2019;1:e44-54.

9. Rosenzwajg M, Lorenzon R, Cacoub P, Pham HP, Pitoiset F, El Soufi K, et al. Immunological and clinical effects of low-dose interleukin-2 across 11 autoimmune diseases in a single, open clinical trial. Ann Rheum Dis. 2019;78:209-17.
10. Miao M, Li Y, Huang B, He J, Li Z. Hypomyopathic dermatomyositis with refractory dermatitis treated by low-dose IL-2. Dermatol Ther (Heidelb). 2020;105:1181-4.

11. Bohan A, Peter JB. Polymyositis and dermatomyositis (first of two parts). N Engl J Med. 1975;292: 344-7.

12. Bohan A, Peter JB. Polymyositis and dermatomyositis (second of two parts). N Engl J Med. 1975;292:403-7.

13. Solomon J, Swigris JJ, Brown KK. Myositis-related interstitial lung disease and antisynthetase syndrome. J Bras Pneumol. 2011;371:100-9.

14. Hoogendijk JE, Amato AA, Lecky BR, Choy EH, Lundberg IE, Rose MR, et al. 119th ENMC international workshop: trial design in adult idiopathic inflammatory myopathies, with the exception of inclusion body myositis, 10-12 October 2003, Naarden, the Netherlands. Neuromuscul Disord. 2004;14(5):337-45.

15. Aggarwal R, Marder G, Koontz DC, Nandkumar P, Qi Z, Oddis CV. Efficacy and safety of adrenocorticotropic hormone gel in refractory dermatomyositis and polymyositis. Ann Rheum Dis. 2018;05(775):720-7.

16. Ichikado K, Suga M, Muranaka H, Gushima Y, Miyakawa H, Tsubamoto $M$, et al. Prediction of prognosis for acute respiratory distress syndrome with thin-section CT: validation in 44 cases. Radiology. 2006;2381:321-9.

17. Rider LG, Giannini EH, Harris-Love M, Joe G, Isenberg D, Pilkington $C$, et al. Defining clinical improvement in adult and juvenile myositis. J Rheumatol. 2003;30:603-17.

18. Rider LG, Giannini EH, Brunner HI, Ruperto N, JamesNewton L, Reed AM, et al. International consensus on preliminary definitions of improvement in adult and juvenile myositis. Arthritis Rheum. 2004;50:2281-90.

19. Aggarwal R, Rider LG, Ruperto N, Bayat N, Erman B, Feldman BM, et al. 2016 American College of Rheumatology/European League Against Rheumatism criteria for minimal, moderate, and major clinical response in adult dermatomyositis and polymyositis: an International Myositis Assessment and Clinical Studies Group/Paediatric Rheumatology International Trials Organisation Collaborative Initiative. Ann Rheum Dis. 2017;76:792-801.

20. Pandya JM, Loell I, Hossain MS, Zong M, Alexanderson $\mathrm{H}$, Raghavan $\mathrm{S}$, et al. Effects of conventional immunosuppressive treatment on CD244+ (CD28null) and FOXP3 $+\mathrm{T}$ cells in the inflamed 
muscle of patients with polymyositis and dermatomyositis. Arthritis Res Ther. 2016;18:80.

21. Saadoun D, Rosenzwajg M, Joly F, et al. Regulatory T-cell responses to low-dose interleukin-2 in HCVinduced vasculitis. N Engl J Med. 2011;365: 2067-77.

22. Rosenzwajg M, Churlaud G, Mallone R, et al. Lowdose interleukin-2 fosters a dose-dependent regulatory $\mathrm{T}$ cell tuned milieu in T1D patients. $\mathrm{J}$ Autoimmun. 2015;58:48-58.

23. Todd JA, Evangelou M, Cutler AJ, et al. Regulatory T cell responses in participants with type 1 diabetes after a single dose of interleukin-2: a non-randomised, open label, adaptive dose-finding trial. PLoS Med. 2016;13:e1002139.

24. Koreth J, Matsuoka K, Kim HT, et al. Interleukin-2 and regulatory $\mathrm{T}$ cells in graft-versus-host disease. N Engl J Med. 2011;365:2055-66.

25. Long SA, Rieck M, Sanda S, et al. Rapamycin/IL-2 combination therapy in patients with type 1 diabetes augments Tregs yet transiently impairs betacell function. Diabetes. 2012;61:2340-8. 